


\title{
Orientação profissional como porta de entrada para psicoterapia: um estudo retrospectivo.
}

\author{
Manoel Antônio dos Santos ${ }^{1,2}$ - Universidade de São Paulo, São Paulo, Brasil \\ Érika Arantes de Oliveira Cardoso - Universidade de São Paulo, São Paulo, Brasil \\ Lucy Leal Melo-Silva - Universidade de São Paulo, São Paulo, Brasil
}

\begin{abstract}
Resumo
O objetivo do presente estudo é caracterizar o perfil sociodemográfico, educacional e clínico dos clientes inscritos em Orientação Profissional que foram encaminhados para psicoterapia em um serviço-escola de psicologia. Foi realizado estudo retrospectivo, baseado em levantamento de prontuários dos clientes atendidos no período 20032006. Os resultados mostraram que foram encaminhados 24 clientes, sendo 20 mulheres (83,3\%), com faixa etária entre 15 e 54 anos, $15(62,5 \%)$ com ensino médio. As queixas que justificaram encaminhamento para psicoterapia foram problemas emocionais/comportamentais, e dificuldades nas relações interpessoais. Dez clientes aderiram até o final do contrato de um ano e tiveram melhora parcial dos sintomas. Conclui-se que a Psicoterapia tem se mostrado um recurso eficiente no atendimento da demanda oriunda da orientação profissional, constituindo uma alternativa complementar para casos que necessitam de abordagem de questões emocionais.

Palavras-chave: orientação profissional; psicoterapia; entrevistas; aconselhamento psicoterapêutico.
\end{abstract}

\section{Vocational Guidance as an entrance door to psychotherapy: a retrospective study}

\begin{abstract}
The objective of this study was to characterize the social demographic, educational and clinical profile of client's from a Vocational Guidance Service, that had been refereed to a Psychotherapy Service in a psychology school. It is a retrospective study. A survey was carried out from an archive of clients attended from 2003 to 2006 . The results showed that 24 clients were refereed, 20 were woman $(83,3 \%)$, aged between 15 an 54, 15 (62,5\%) had finished high school. The complaints that indicated psychotherapy were difficulties with professional, family and emotional relationships. Nine (37,5\%) did not attend the assessment interview and 13 (54,2\%) started psychotherapy. Ten clients completed one year of treatment contracted and showed partial improvement of symptoms. The conclusion is that the psychotherapy has showed as an efficacious resource in attending vocational guidance demands, thus constituting a complementary alternative for the cases that need to get into emotional matters.
\end{abstract}

Keywords: vocational guidance; psychotherapy; interviews; psychotherapeutic counseling.

\section{Introdução}

A escolha da carreira é tipicamente um problema do domínio da Orientação Vocacional/ Profissional $(\mathrm{OVP})^{3}$ ou do Aconselhamento de Carreira (AC). Porém, na prática cotidiana muitas vezes o orientador profissional se defronta com problemas de escolha ou de decisões sobre a carreira de seus clientes que se configuram, também, como demanda por intervenção psicoterápica ou de aconselhamento pessoal (AP).

A orientação vocacional/profissional (OVP) constitui uma ampla gama de procedimentos e tarefas, que incluem o diagnóstico, a investigação, a prevenção e a solução da problemática relacionada ao campo vocacional. Segundo Bohoslavsky (2003), pode-se entender como orientação vocacional (OV): os procedimentos dos psicólogos especializados, cujos clientes são as pessoas que enfrentam, em determinado momento de sua vida - em geral de um ciclo educativo a outro -, a possibilidade e a necessidade de tomar decisões. Isso faz da escolha um momento crítico de mudança na vida dos indivíduos. De como as pessoas enfrentam e elaboram essa mudança dependerá o desenvolvimento posterior, a situar-se em algum ponto do continuum que vai da saúde à doença, como quer que elas sejam concebidas.

Nessa perspectiva, o profissional da área tenta ajudar seus clientes a assumirem de forma ativa a problemática atual que enfrentam de forma a compreendê-la e chegar a uma decisão autônoma. Assim, pode-se definir a orientação vocacional como sendo a "colaboração não diretiva com o cliente, no

\footnotetext{
${ }^{1}$ Agradecimento: Os autores agradecem a colaboração do aluno Fabio Pagotto Piovesani na etapa de coleta dos dados.

${ }^{2}$ Endereço para correspondência:

Departamento de Psicologia e Educação da Faculdade de Filosofia, Ciências e Letras - Universidade de São Paulo (FFCLRP/USP)

Av. Bandeirantes, 3900 - 14040-901 - Ribeirão Preto-SP, Brasil.

E-mail: masantos@fffclrp.usp.br

3 Orientação Profissional Vocacional e/ou de Carreira são conceitos mais utilizados no contexto brasileiro, enquanto que, internacionalmente, utilizam-se mais os conceitos career counseling e personal counseling.
} 
sentido de restituir-lhe uma identidade e/ou promover o estabelecimento de uma imagem não conflitiva de sua identidade profissional" (Bohoslavsky, 2003, p. 5).

A dificuldade na tomada de decisão de carreira pode ser entendida como um problema também de personalidade, como salientou Bohoslavsky (1971/1991). Assim sendo, refletir sobre a interface entre as duas modalidades de atendimento psicológico $(\mathrm{OV} / \mathrm{P}$ e $\mathrm{AC})$ é útil para se ter clareza a respeito dos encaminhamentos necessários.

A orientação vocacional/profissional (OVP) ou aconselhamento de carreira (Career Counseling) seria fundamentalmente diferente da psicoterapia ou do aconselhamento pessoal (Personal Counseling)? Em que essas modalidades de intervenção se aproximam e em que se diferenciam? Há um debate intenso na literatura com relação a esse assunto, indicando como questões pessoais fazem intersecção com o aconselhamento de carreira e como é problemático separar esses dois campos como se fossem compartimentos estanques. Nesse sentido, Swanson (1995) defende explicitamente a necessidade de integração entre aconselhamento de carreira e psicoterapia.

Um estudo de Hackett (1997) também aponta para essa direção. Apesar de propor uma distinção entre AP e AC, Hackett (1997) encoraja a busca de integração entre as questões de carreira e as questões pessoais no processo de aconselhamento. Swanson (1995) vai ainda mais longe, quando adverte que qualquer tentativa de compartimentalizar a vida dos clientes seria um desserviço que estaríamos prestando a eles. Já Betz e Corning (1993) também arguiram pela indissolubilidade entre questões de carreira e questões pessoais no aconselhamento, utilizando as variáveis de gênero e "raça" para ilustrar a necessidade de uma abordagem holística.

Por sua vez, Spokane (1989) propôs um modelo no qual os dois domínios - questões de trabalho e de saúde mental - coexistem, mas não se interceptam, exceto em momentos de maior estresse ou de transição psicossocial. Esse modelo inclui fatores de risco e estratégias de enfrentamento que influenciam e são influenciados por dificuldades de decisão de carreira. O referido autor propõe que os dois domínios devem ser entendidos como independentes antes de se ter uma resolução de carreira, porém convergem durante tal tomada de decisão e então se separam novamente após a mesma.

A distinção entre questões de carreira e questões pessoais - e, portanto, entre AC e AP pode ser reforçada pelas percepções que temos acerca do AC. Há críticas a uma visão estereotipada de AC, que desvaloriza seu componente psicológico, o que afeta tanto a oferta como a qualidade de serviços de AC (Manuele-Adkins, 1992). Nessa visão estereotipada, o AC é visto como um processo eminentemente cognitivo e racional; por essa razão há uma ênfase sobre a testagem, que forneceria informações objetivas sobre o indivíduo e a oferta de sistemas computacionais que mediariam o processo. Nessa concepção particular o AC tem duração breve, portanto é limitado quanto à extensão de possíveis estratégias de intervenção que podem ser utilizadas. Além disso, essa visão obscurece processos psicológicos subjacentes, tais como a indecisão que dificulta a escolha, e considera que o AC é diferente do AP - então, acaba rebaixando o valor do AC e alimentando uma falsa separação entre trabalho $\mathrm{e}$ não-trabalho.

Para Swanson (1995), é problemático dicotomizar a intervenção desse modo, pois essa concepção nos leva a pensar que AC e AP funcionariam com esquemas cognitivos distintos. $\mathrm{Na}$ verdade, sabemos que o AP é um processo muito amplo, incluindo elementos que não são diretamente relacionados à carreira. A definição implícita de AC, por outro lado, é muito estreita, consistindo primariamente nas escolhas de uma carreira inicialmente feita por jovens adultos, negligenciando, portanto, o ajustamento necessário ao mundo adulto do trabalho.

O aconselhamento de carreira frequentemente se processa em um campo (pessoal ou de carreira) sem que haja reverberação de questões potenciais no outro campo, e com frequência um cliente pode procurar ambos os tipos de serviços simultaneamente. Diversos estudos, contudo, sugerem que, na prática, é incomum que clientes com questões de carreira sejam muito diferentes de clientes que procuram ajuda com problemas pessoais. Lucas (1992) relatou que estudantes que buscam ajuda por questões de carreira não são fundamentalmente diferentes daqueles que procuram atendimento motivados por questões pessoais. Gold e Scanlon (1993) também mostraram que estudantes com questões não relacionadas à carreira não tinham mais estresse psicológico do que estudantes com questões de carreira, ainda que os primeiros recebessem duas vezes mais sessões de aconselhamento.

Osipow e Gold (1968) confirmaram que estudantes que requisitaram AP também tinham dificuldades de desenvolvimento de carreira, quando comparados com um grupo controle. A partir dessas evidências da literatura vários autores têm apresentado sugestões para integrar em uma única 
proposta de intervenção questões de carreira e questões pessoais.

No contexto português, Nascimento e Coimbra (2005a) destacam que os pedidos dos clientes, isto é, os motivos que os levam a procurar assistência em orientação profissional, muitas vezes se apresentam inespecíficos, até mesmo porque essas pessoas não conseguem, muitas vezes, identificar as suas necessidades dominantes, sendo comum vivenciarem os pedidos vocacionais como menos estigmatizantes e, desta forma, mais aceitáveis do que os psicoterápicos (Carvalho, 1995; Davidson \& Gilbert, 1993; Imaginário \& Campos, 1987).

Por sua vez, Bohoslavsky (2003), com base na estratégia clínica que parte de um referencial psicodinâmico, no contexto argentino, aponta que um problema de decisão é também um problema de personalidade. Também no contexto argentino e clínico-operativo Müller (2007) aponta que a OP cumpre importante papel, tanto na perspectiva de promoção de saúde quanto na perspectiva terapêutica. Da perspectiva preventiva, ou de promoção de saúde, se insere em processos de aprendizagem sistemáticos, como a escola, por exemplo, e assistemáticos, em diversas situações de mudanças de vida nas quais possibilita reflexões sobre si e, indubitavelmente, a exploração da personalidade. Da perspectiva terapêutica, a orientação vocacional:

aborda situações conflitivas que podem comprometer toda a personalidade, pois tem relação com a identidade e as mudanças, e com tudo que mobiliza e desestrutura. Ademais, elabora um projeto vocacional-ocupacional põe a descoberto a problemática do sujeito e suas disposições psicopatológicas, pois condensa toda a história prévia dessa pessoa e, o mesmo tempo antecipa o futuro (Müller, 2007, p. 5).

A despeito de haver distinções de ordem epistemológica, há pontos em comum entre os autores que selecionamos. Guardadas as devidas diferenças, esses referenciais teóricos convergem ao considerarem a proximidade entre os campos da orientação vocacional e da psicoterapia, como apontado anteriormente.

Nota-se, assim, que diversos estudiosos têm se mobilizado para esclarecer as demandas específicas do potencial cliente de OVP. São necessárias publicações qualificadas sobre essa temática, o que justifica a proposta da presente investigação. Estudos que sistematizem dados dos serviços obtidos em condições naturalísticas e que se debruçam sobre o perfil da clientela, fluxo de atendimento, taxas de adesão e abandono são importantes para apoiar e enriquecer a investigação das variáveis institucionais que influenciam a aliança cliente-terapeuta (Llulhier $\&$ Nunes, 2004).

Nessa vertente, este estudo visa proporcionar subsídios que favoreçam o planejamento de ações e programas voltados para o atendimento à clientela que apresenta demanda inicial por OP coexistindo com demandas por procedimentos psicoterápicos, em um serviço-escola de um curso de psicologia mantido por uma universidade pública como uma modalidade de formação prática do psicólogo e de prestação de serviços à comunidade.

Situando-se na interface da OVP e do atendimento psicoterapêutico, o presente estudo tem por objetivo caracterizar o perfil sociodemográfico, educacional e clínico dos clientes inscritos em um Serviço de OP, que foram encaminhados ao Serviço de Psicoterapia de uma clínica-escola de um curso de psicologia de uma universidade pública do estado de São Paulo, Brasil.

\section{Método}

Trata-se de um estudo descritivo e exploratório, na modalidade de pesquisa retrospectiva documental. A fim de contextualizar o universo das práticas psicológicas, serão descritos, a seguir, os serviços de: (1) Orientação Vocacional/Profissional, (2) Triagem para Atendimento Psicológico e (3) Psicoterapia do Centro de Pesquisa e Psicologia Aplicada (CPA) da Faculdade de Filosofia, Ciências e Letras de Ribeirão Preto (FFCLRP) da Universidade de São Paulo (USP).

\section{Serviço de Orientação Vocacional/ Profissional}

A OVP é um campo de intervenção e pesquisa em franca expansão na contemporaneidade. No contexto brasileiro tem havido avanço em estudos de sistematização de dados relativos aos serviços de atendimento à comunidade, no domínio da OVP, prestados por cursos de graduação em psicologia, como parte da estratégia de formação e qualificação do aluno. $\mathrm{O}$ atendimento oferecido nesse contexto de formação visa, em primeira instância, oferecer um campo de estágio profissionalizante para treinamento de habilidades e competências específicas do aluno. Por outro lado, a população atendida é beneficiária direta desse processo de formação do futuro profissional de psicologia.

$\mathrm{O}$ atendimento realizado no Serviço de Orientação Profissional (SOP) do CPA fundamentase no referencial clínico-operativo (Antunes, Valdo \& Melo-Silva, 2003; Melo-Silva, 1999; Melo-Silva \& Jacquemin, 2001). O método clínico-operativo integra 
as contribuições de Bohoslavsky (2003), Müller (1988; 1994) e Pichon-Rivière (1994; 1995). Para a modalidade de atendimento individual a concepção de estratégia clínica mostra-se bastante adequada, pois se caracteriza por ser "uma estratégia de abordagem do objeto de estudo, que é o comportamento humano" (Bohoslavsky, 2003, p. 6). Esse processo inclui três momentos: ver, pensar e atuar psicologicamente, ou seja, a observação ou investigação, o diagnóstico e o tratamento. Essa tríplice dimensão deve ser integrada à concepção de formação do psicólogo, em geral, e do orientador vocacional/profissional em especial.

Para se alcançar esse objetivo, o orientador realiza predominantemente entrevista clínica na modalidade de intervenção individual. Além disso, ele pode se amparar em atividades que incluem aplicação de técnicas objetivas e expressivas, além de outros recursos. É nessa perspectiva que o SOP tem desenvolvido suas estratégias de intervenção individual ou grupal aos interessados que se inscrevem no serviço, após o processo de triagem.

$\mathrm{Na}$ inscrição para atendimento os candidatos a clientes recebem um formulário para ser preenchido. Esse documento é assinado pelo usuário e por um de seus responsáveis, no caso de ser menor de 18 anos. O formulário dá ciência do atendimento a ser realizado e os signatários, por meio desse instrumento, autorizam ou não a eventual utilização dos dados para a realização de pesquisas, cujos resultados poderão ser divulgados e utilizados em aulas ou eventos científicos, preservando-se o anonimato e o caráter sigiloso das informações fornecidas (Melo-Silva, 1999; 2005). Desse modo, assegura-se a não-identificação do orientado. $O$ cliente, seguindo a ordem de inscrição, é convocado para uma entrevista de triagem. Concluída a entrevista, o estagiário faz as anotações necessárias, define se a situação é de orientabilidade (Bohoslavsky, 2003) e registra sua indicação para orientação profissional individual ou em grupo. A modalidade grupal é a preferencial, já que, por sua própria característica, disponibiliza maior número de vagas. Quando necessário, procede-se ao encaminhamento do caso para psicodiagnóstico e/ou psicoterapia na própria clínica-escola ou em outros recursos da comunidade local.

Desde sua implementação, existe uma articulação entre o SOP e os demais serviços: de triagem de adolescentes e adultos, de psicodiagnóstico e de atendimento psicoterápico, objetivando a definição de propostas de encaminhamento mais adequadas à situação de cada cliente. Ocorre, na prática, uma separação do atendimento em OP e em
Psicoterapia, mas essa separação se restringe a situações que requerem intervenção no plano emocional e comportamental com maior premência do que nas questões de carreira, uma vez que se detecta comprometimento psíquico acentuado. Tal qual apontado por Müller (2007), quando se detectam sintomas que afetam a personalidade, abordagens psicoterapêuticas específicas são necessárias. Para Casullo e cols. (2006)

um conflito na tomada de decisão deve ser considerado como um sintoma de uma problemática mais profunda, que pode ser tratada na prática com um dispositivo analítico por um psicanalista (p. 68).

Em outras situações - que não são objeto deste estudo - ocorre intervenção na interface dessas modalidades, conforme apontado anteriormente. Evidentemente, as indicações são estabelecidas em comum acordo com o candidato, considerando suas possibilidades e disponibilidade para engajamento no serviço indicado, segundo as vagas disponíveis.

Normalmente, o encaminhamento dos clientes do SOP para o SP é efetuado durante o período de realização das entrevistas de triagem. A decisão sobre o encaminhamento é tomada com base na opinião: (1) do psicólogo-estagiário que realizou a entrevista inicial; (2) da supervisora do SOP; (3) da psicóloga do SP e, principalmente, (4) do cliente. Se o cliente está de acordo com essa indicação, é efetuado o encaminhamento. Caso não concorde, ele é atendido no SOP na modalidade individual, sendo designado para acompanhá-lo um estagiário, que atuará na interface OP/Psicoterapia. Preferencialmente, a porta de entrada para o atendimento psicológico no CPA é efetivada por meio de um serviço. Ambas as equipes avaliam os benefícios potenciais para o cliente e as disponibilidades de vagas e horários nos serviços. Havendo vaga, há possibilidade de o cliente ser atendido concomitantemente no SOP e no SP. Nesse caso, a indicação é para modalidade de intervenção em grupo no SOP. Há situações nas quais as questões de carreira são mais prementes e, então, o cliente é atendido, primeiramente, no SOP e, posteriormente, é encaminhado para o SP. As entrevistas iniciais constituem situações diagnósticas por excelência, pois são úteis para explicitar o pedido do cliente como ponto de partida e, ao mesmo tempo, possibilitar a avaliação técnica que subdiará a indicação de intervenção.

\section{Triagem para atendimento psicológico}

A literatura aponta que a triagem deve ser compreendida já como uma etapa de atendimento 
psicológico a uma pessoa em sofrimento e/ou vivenciando crises evolutivas. Nesse processo de acolhimento do usuário, que não se constitui necessariamente em um único contato ou técnica investigativa, pode-se tomar conhecimento do motivo de consulta ("queixa") e das expectativas de quem busca ajuda. Observa-se, assim, que há uma finalidade diagnóstica nessa etapa inicial.

$\mathrm{Na}$ Clínica Psicológica do Centro de Pesquisa e Psicologia Aplicada o processo de triagem para a clientela adulta e adolescente está sob a responsabilidade de uma psicóloga da instituição. Todos os clientes inscritos ou encaminhados são submetidos a uma entrevista individual de triagem, orientada por um roteiro semiestruturado. Esse instrumento foi padronizado e aperfeiçoado ao longo dos anos, de modo a se adequar aos objetivos de discriminar a demanda do cliente, identificar sua motivação e suas reais necessidades em relação às possibilidades do serviço, considerando-se os modelos de atendimento oferecidos. O roteiro de entrevista focaliza os motivos que justificam a procura ("queixa" manifesta e latente), a gênese e evolução da problemática emocional e/ou comportamental, bem como suas consequências para o processo adaptativo do cliente (Santos \& Oliveira, 2005).

A entrevista de triagem tem duração de aproximadamente 60 minutos. No caso de adolescentes - usuários de 12 a 18 anos incompletos - o processo só é realizado após autorização formal (por escrito) dos pais ou responsáveis legais, como apontado anteriormente. Os clientes, assim como seus responsáveis legais, assinam um Termo de Consentimento Livre e Esclarecido, mediante o qual autorizam a utilização dos dados como material didático e de estudos, resguardado o compromisso ético com o sigilo e o anonimato.

O roteiro de entrevista de triagem foi delineado especialmente para atender os objetivos de seleção do cliente para as modalidades de atendimento psicoterápico oferecidas na instituição, cuja condução, basicamente, está sob a responsabilidade de estagiários do quarto e quinto anos do curso de graduação. Uma vez concluída a entrevista, é formulada uma hipótese diagnóstica, e com base nessa formulação é determinada a conduta indicada para o caso, como foram feitos os encaminhamentos de cada situação objeto deste estudo.

\section{O Serviço de Psicoterapia}

Em relação às características psicossociais da clientela-alvo atendida no SP, trata-se de uma população adulta, com idade superior a 12 anos, com grau de escolaridade e nível profissional diversificado. Os clientes provêm, geralmente, de camadas sociais desprivilegiadas do ponto de vista socioeconômico. Atendem-se, predominantemente, situações clínicas de transtornos situacionais, neuróticos e desvios de conduta, excluindo-se do seguimento situações diagnosticadas como: psicose, deficiência mental e distúrbios orgânicos, bem como alcoolismo e dependência de drogas ilícitas, pelo fato de que não se adaptam à proposta de trabalho e dela aufeririam resultados bastante limitados. Em relação à problemática apresentada como justificativa para o atendimento, de um modo geral predominam as dificuldades de relacionamento interpessoal e uma gama variada de problemas afetivos (Santos, Pasian, Oliveira, Melo-Silva \& Garducci, 2005). Predominam abordagens de atendimento individual, com frequência semanal, de uma ou duas sessões, seguindo teorias específicas, centradas na psicoterapia de orientação psicanalítica, na abordagem centrada na pessoa ou na psicologia analítica (psicoterapia junguiana).

Considerando a orientação teórica do atendimento psicoterápico junto à clínica psicológica, cumpre assinalar que são três serviços distintos: de orientação psicanalítica, abordagem centrada na pessoa e psicoterapia junguiana. Os clientes são selecionados pelo Serviço de Triagem e distribuídos de acordo com o perfil psicológico e as disponibilidades de vagas. O serviço de psicoterapia de orientação psicanalítica oferece maior número de vagas e é coordenado pelos autores do presente estudo, o que justifica o interesse por investigá-lo, a partir de uma fundamentação teórica psicodinâmica.

Em geral, os clientes permanecem sob atendimento pelo período de um ano, podendo até, em alguns casos, ser reconduzidos para o ano letivo seguinte, mas esse prolongamento da assistência não corresponde à maioria dos casos atendidos. O seguimento individual dos casos, na prática, acaba tendo a duração de aproximadamente 10 meses (de março a dezembro do ano letivo em curso). Os clientes que expressam desejo de prosseguir o processo psicoterápico são encaminhados para atendimento em outros serviços ou mesmo em consultório privado, com profissionais cadastrados na Clínica, que se dispõem a cobrar um valor acessível e condizente com o poder aquisitivo da população assistida (Santos \& Oliveira, 2005).

\section{Amostra}

A amostra deste estudo foi constituída pelos clientes $(n=24)$ cadastrados no Serviço de Orientação Profissional, que foram encaminhados para o Serviço de Psicoterapia, no período de janeiro de 2003 a dezembro de 2006. 


\section{Procedimento}

Foi realizado um levantamento dos prontuários individuais dos clientes atendidos nos dois serviços envolvidos na investigação durante um período de quatro anos (2003-2006). Os dados foram extraídos dos roteiros de entrevista preenchidos no momento da triagem e de outros formulários de atendimento arquivados na Instituição. Foi construído um formulário para sistematização das informações obtidas na revisão dos prontuários dos clientes. Foram coletadas as informações sobre o atendimento e a identificação dos clientes, como: sexo, idade e nível de escolaridade no momento da triagem.

Os dados de cada cliente foram organizados em cinco categorias, sendo, posteriormente, realizada a tabulação e o cálculo da média dos resultados quantitativos, visando à obtenção do perfil sociodemográfico, educacional e clínico dos clientes inscritos no SOP e encaminhados ao SP. As categorias são: (1) fluxo de atendimento no SOP e SP; (2) perfil sociodemográfico; (3) justificativa apresentada pelo serviço de OP para o encaminhamento para o SP (queixas apresentadas pelos clientes); (4) itinerário terapêutico; e (5) desfecho do atendimento.

\section{Resultados}

Fluxo de atendimento no SOP e SP

No período de janeiro de 2003 a dezembro de 2006 foram cadastrados nos serviços de Orientação Profissional e de Psicoterapia 1.157 clientes. No ano de 2003 foram atendidos 409 clientes, em 2004 foram 216, em 2005 foram 221 e em 2006 foram 311 clientes, a maioria no Serviço de Orientação $(72 \%)$ Profissional, como pode ser observado na Tabela 1. No período abrangido pelo presente estudo apenas um cliente foi atendido, concomitantemente, por ambos os serviços.

Tabela 1 - Distribuição dos clientes atendidos no Serviço de Orientação Profissional (SOP) e Serviço de Psicoterapia (SP) em função do ano de inscrição $(N=1157)$

\begin{tabular}{cccc}
\hline Ano & SOP & $S P$ & Total \\
\hline 2003 & $293(72 \%)$ & $116(28 \%)$ & 409 \\
2004 & $171(79 \%)$ & $45(21 \%)$ & 216 \\
2005 & $128(58 \%)$ & $93(42 \%)$ & 221 \\
2006 & $243(78 \%)$ & $68(22 \%)$ & 311 \\
\hline Total & $835(72 \%)$ & $322(28 \%)$ & 1157 \\
\hline
\end{tabular}

No período abrangido pelo levantamento (2003-2006) foram encaminhados 24 clientes do SOP para o SP, aproximadamente $3 \%$ dos clientes atendidos pelo SOP. A distribuição desses casos encaminhados ao longo dos quatro anos encontra-se sistematizada na Tabela 2. Os participantes desse estudo representam 2,9\% dos inscritos no SOP e $7,5 \%$ dos inscritos no SP. Observa-se que o número de encaminhamentos do SOP para o SP decresceu no período. Cumpre esclarecer que, na década de 1990 , esse número era maior e que, no SOP, têm sido feitos investimentos no sentido de informar à comunidade a natureza do serviço. Assim, infere-se que a diminuição pode ser decorrência de melhor divulgação da natureza e finalidade do serviço para a comunidade que o utiliza.

Tabela 2 - Distribuição dos clientes encaminhados do Serviço de Orientação Profissional para o Serviço de Psicoterapia em função do ano de inscrição e da porcentagem em relação ao número de usuários do SOP e do SP $(\mathrm{N}=24)$

\begin{tabular}{cccc}
\hline Ano & $N$ & $\%$ SOP & $\%$ SP \\
\hline 2003 & 11 & 3,8 & 9,5 \\
2004 & 6 & 3,5 & 13,3 \\
2005 & 5 & 3,9 & 5,4 \\
2006 & 2 & 0,8 & 2,9 \\
\hline Total & 24 & 2,9 & 7,5 \\
\hline
\end{tabular}

Perfil sociodemográfico

Observa-se que no período considerado pelo estudo foram encaminhados 24 clientes (Tabela 3), dentre os quais 20 eram mulheres $(83 \%)$ e quatro homens $(17 \%)$. Esses dados refletem a proporção desigual entre os gêneros na demanda por orientação profissional. A faixa etária variou de 15 a 54 anos, com uma média de 27,5 anos. Considerando que o SOP é procurado predominantemente por adolescentes na faixa etária de 17 anos, observa-se a necessidade de psicoterapia especialmente pela clientela na idade adulta. Quanto ao nível de escolaridade, 15 clientes $(62,5 \%)$ tinham ensino médio completo ou em curso. Nove clientes $(37,5 \%)$ tinham ensino superior e poderiam apresentar também demanda por reorientação de carreira. Em relação ao estado marital, 17 eram solteiros (71\%), quatro divorciados (17\%) e três casados (12\%). Essa distribuição é consistente com a faixa etária desses clientes. No que diz respeito à profissão/ocupação dos clientes encaminhados para psicoterapia, 11 (46\%) eram estudantes, cinco vendedores (21\%), um engenheiro (4\%), um administrador de empresa $(4 \%)$ e uma advogada (4\%). Observou-se que cinco $(21 \%)$ estavam desempregados. 
Tabela 3 - Caracterização dos clientes encaminhados pelo Serviço de Orientação Profissional para o Serviço de Psicoterapia entre janeiro de 2003 e dezembro de $2006(\mathrm{~N}=24)$

\begin{tabular}{|c|c|c|}
\hline Variáveis & $N$ & $\%$ \\
\hline \multicolumn{3}{|l|}{ Sexo } \\
\hline Masculino & 4 & 17,0 \\
\hline Feminino & 20 & 83,0 \\
\hline Total & 24 & 100,0 \\
\hline \multicolumn{3}{|l|}{ Faixa etária } \\
\hline $15-21$ & 19 & 79,0 \\
\hline $21-54$ & 5 & 21,0 \\
\hline \multicolumn{3}{|l|}{ Escolaridade } \\
\hline Ensino médio & 15 & 62,5 \\
\hline Ensino superior (em curso) & 6 & 25,0 \\
\hline Ensino superior completo & 3 & 12,5 \\
\hline \multicolumn{3}{|l|}{ Estado Marital } \\
\hline Solteiro & 17 & 71,0 \\
\hline Divorciado & 4 & 17,0 \\
\hline Casado & 3 & 12,0 \\
\hline \multicolumn{3}{|l|}{ Profissão/ocupação } \\
\hline Estudante & 11 & 46,0 \\
\hline Vendedor & 5 & 21,0 \\
\hline Engenheiro & 1 & 4,0 \\
\hline Administrador de empresa & 1 & 4,0 \\
\hline Advogado & 1 & 4,0 \\
\hline Desempregado & 5 & 21,0 \\
\hline
\end{tabular}

Justificativas para o encaminhamento

As queixas que justificaram o encaminhamento para psicoterapia foram agrupadas em três categorias: (1) problemas emocionais e comportamentais, (2) dificuldades nas relações interpessoais, e (3) dificuldades escolares. As queixas emergentes na entrevista inicial foram organizadas em categorias para fins didáticos, objetivando delinear o diagnóstico da demanda do cliente e maximizar as possibilidades de o atendimento psicológico resultar eficaz. É importante ressaltar que essas categorias, sobretudo 1 e 2, não são mutuamente excludentes e que a queixa principal, na perspectiva do entrevistado, é que foi computada nessa sistematização. Com o objetivo de ilustrar tais queixas, algumas falas literais dos clientes foram extraídas dos prontuários e organizadas segundo as categorias de análise.

1. Problemas emocionais e comportamentais $(\mathrm{n}=13)$

Eu acho que sempre fui tímido, mas na escola, se eu tenho que dar um seminário, é um sofrimento, eu tenho dores de barriga, não durmo na véspera, tenho a sensação de que vou desmaiar. (16 anos, estudante, feminino)

Eu me sinto sozinho no mundo, tenho a minha familia, mas mesmo com eles me sinto muito sozinho. (19 anos, vendedor, masculino)

Eu ando desanimado, com vontade de não fazer nada, de dormir para sempre, uma tristeza imensa que não sei de onde vem... (20 anos, desempregado, masculino)

De uns tempos para cá acho que eu sou pior, assim, menos capaz do que qualquer pessoa; sempre acho que os outros são melhores do que eu. (19 anos, desempregada, feminino)

Apareceram-me muitas dores pelo corpo, o corpo todo... e o médico disse que tem um fundo emocional. (54 anos, desempregado, feminino).

Dificuldades nas relações interpessoais $(n=9)$, que muitas vezes são simultâneas ou decorrentes das queixas anteriores

2.1 - No trabalho

Só de pensar em ir para o trabalho é um tormento, eu tenho muita dificuldade em conviver com aquelas pessoas, acho que estão sempre procurando algo que en fiz que possa me prejudicar. (22 anos, vendedor, masculino)

\section{2 - Na família}

Lá em casa é tudo difícil, ninguém me entende... estão sempre me cobrando, ninguém pára para ver o meu lado. (17 anos, estudante, feminino)

2.3 - Nas relações amorosas

Eu nunca consigo levar adiante uma relação, começa bem, depois vem a insegurança, os ciúmes e eu acabo estragando tudo. (18 anos, estudante, feminino)

3 - Dificuldades escolares $(\mathrm{n}=2)$

Eu tento prestar atenção no que o professor falou, mas aí parece que dá um branco. Acho que estou com problemas de memória e o vestibular já tá aí... (17 anos, estudante, feminino)

Ao considerar os motivos relatados pelos clientes como justificativa para a busca do atendimento psicológico, a equipe do SOP avaliou que os clientes teriam maior benefício com uma intervenção psicoterápica, uma vez que os problemas relacionados anteriormente não constituem o foco do processo de orientação vocacional/ profissional. 


\section{Itinerário terapêutico}

Dos 24 clientes, dois $(8 \%)$ foram encaminhados para clínicas particulares, como mostra a Tabela 4, e os demais, $22(92 \%)$, foram referidos para o SP, dentre os quais nove $(41 \%)$ não compareceram à entrevista inicial - no presente trabalho serão denominados de "desistentes" - e 13 deles $(59 \%)$ foram selecionados e logo em seguida iniciaram atendimento no SP. Desses 13 clientes, 11 iniciaram o atendimento psicoterápico.
A Tabela 4 informa que, dos 13 clientes que compareceram à entrevista inicial, 11 eram do sexo feminino $(78 \%)$. A idade prevalente variou de 15 a 21 anos (70\%). Em relação ao nível de escolaridade, oito $(62 \%)$ tinham completado o ensino médio, três $(23 \%)$ tinham ensino superior completo e dois $(15 \%)$ ensino superior em andamento. Seis clientes (46\%) tinham os estudos como única ocupação. Quanto ao estado marital, 10 (77\%) eram solteiros, dois divorciados e um casado.

Tabela 4 - Caracterização dos clientes encaminhados do SOP para o SP que compareceram e que não compareceram à entrevista inicial $(\mathrm{N}=9)$

\begin{tabular}{|c|c|c|c|c|}
\hline & \multicolumn{2}{|c|}{ Compareceram } & \multicolumn{2}{|c|}{ Não compareceram } \\
\hline $\begin{array}{l}\text { Variáveis } \\
\text { Sexo }\end{array}$ & $\bar{N}$ & $\%$ & $N$ & $\%$ \\
\hline Masculino & 2 & 22,0 & 7 & 78,0 \\
\hline Feminino & 11 & 78,0 & 2 & 22,0 \\
\hline Total & 3 & 100,0 & 9 & 100,0 \\
\hline Faixa etária & $\begin{array}{l}9 \\
4\end{array}$ & $\begin{array}{l}70,0 \\
30.0\end{array}$ & $\begin{array}{l}8 \\
1\end{array}$ & $\begin{array}{l}89,0 \\
110\end{array}$ \\
\hline Escolaridade & & & & \\
\hline Ensino Médio & 8 & 62,0 & 5 & 55,5 \\
\hline Ensino Superior (andamento) & 2 & 15,0 & 3 & 33,5 \\
\hline $\begin{array}{l}\text { Ensino Superior concluído } \\
\qquad \text { Estado Marital }\end{array}$ & 3 & 23,0 & 1 & 11,0 \\
\hline Solteiro & 10 & 77,0 & 7 & 78,0 \\
\hline Divorciado & 2 & 15.0 & 1 & 11,0 \\
\hline Casado & 1 & 8,0 & 1 & 11,0 \\
\hline Profissão/ocupação & & & & \\
\hline Estudante & 6 & 46,0 & 8 & 89,0 \\
\hline Vendedor & 3 & 23,0 & - & 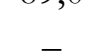 \\
\hline Administrador de empresa & 1 & 8,0 & - & - \\
\hline Engenheiro & 1 & 8,0 & - & - \\
\hline Desempregado & 2 & 15,0 & $\overline{1}$ & $1 \overline{1}, 0$ \\
\hline
\end{tabular}

Em relação aos clientes desistentes, conforme mostra a Tabela 4, sete eram mulheres (78\%). A idade prevalente variou entre 15 e 21 anos $(89 \%)$. Cinco cursavam o ensino médio, três estavam cursando faculdade, um tinha nível superior completo; portanto, oito dos nove desistentes eram estudantes. Em relação ao estado marital, sete eram solteiros (78\%), um era casado e um divorciado.

\section{Desfecho do atendimento}

Dois dos clientes que compareceram à entrevista inicial se recusaram a dar início ao atendimento psicológico. Um justificou alegando que não precisava de apoio psicológico e que só desejava uma orientação profissional; o outro alegou não ter disponibilidade de tempo para realizar o atendimento. Ao primeiro foi sugerido que retornasse ao SOP, onde foi atendido dentro das suas possibilidades. Desse modo, 11 clientes aceitaram o encaminhamento para o atendimento psicoterápico, como mostra a Tabela 5. Dez clientes aderiram e permaneceram até o final do contrato de um ano de atendimento. Um desistiu após o quarto encontro, alegando não ter mais interesse no atendimento.

No período analisado foram realizadas 441 sessões de atendimentos, 44 sessões em média por cliente, com um total de 63 faltas, sendo que uma única cliente chegou a faltar em 23 sessões, apresentando diferentes justificativas que a protegeram do desligamento compulsório que seria aplicado por infringir seguidamente uma regra do contrato, que prevê interrupção do atendimento no caso de três faltas injustificadas consecutivas ou de cinco faltas injustificadas alternadas. 
Tabela 5 - Evolução dos atendimentos dos clientes encaminhados do SOP para o SP $(\mathrm{N}=11)$.

\begin{tabular}{|c|c|c|}
\hline Variáveis & Freqüência & $\%$ \\
\hline \multicolumn{3}{|l|}{ Aderiram ao atendimento } \\
\hline $\operatorname{Sim}$ & 10 & 78,0 \\
\hline Não & 1 & 22,0 \\
\hline Total & 11 & 100,0 \\
\hline \multicolumn{3}{|l|}{ Sessões ocorridas } \\
\hline Total & 441 & _- \\
\hline Média por cliente & 44 & - \\
\hline Faltas & 63 & _- \\
\hline Avaliação final & & \\
\hline Melhora parcial & 10 & 100,0 \\
\hline Melhora total & _ & - \\
\hline $\begin{array}{l}\text { Agravamento dos sintomas } \\
\text { Encaminhamentos após um ano }\end{array}$ & - & - \\
\hline Clínica particular & 7 & 70,0 \\
\hline Outras instituições & 3 & 30,0 \\
\hline
\end{tabular}

De acordo com as anotações contidas nos prontuários, os clientes que concluíram o atendimento no Serviço obtiveram melhora parcial das queixas que motivaram a indicação para psicoterapia e receberam encaminhamento, após um ano de tratamento para recursos externos à universidade, como clínicas particulares e outros serviços institucionalizados.

\section{Discussão}

A caracterização do perfil sociodemográfico da clientela mostra maior incidência de procura de atendimento por parte do sexo feminino, o que corrobora achados da literatura que mostram que as mulheres buscam mais os serviços de saúde de um modo geral e, em especial, os serviços de saúde mental. Essa maior incidência de mulheres na clínica psicológica/psicoterápica está relacionada, entre outros fatores, a determinadas construções de gênero. Ao sexo feminino são atribuídas características, qualidades e atributos, tais como maior sensibilidade, afetividade e permissividade para expressão livre e franca das emoções, além de maior interesse pelas questões próprias do mundo subjetivo. Ainda segundo essas construções socioculturais, o gênero feminino estaria mais propenso a buscar ajuda, pois a mulher é educada para cuidar das relações humanas e valorizálas. Essa mesma concepção enfatiza que o homem seria mais resistente à abordagem de seus aspectos afetivo-emocionais, pois teria maiores dificuldades de entrar em contato com sua interioridade e sua dimensão emocional; isso o tornaria menos propenso a envolver-se em uma jornada introspectiva de busca do autoconhecimento, como é a proposta da psicoterapia.

Outro dado saliente no perfil desses clientes é a idade. Considerando que o SOP é procurado predominantemente por adolescentes, a busca espontânea por parte de pessoas adultas chama a atenção. Visando atender a essa população, um programa de reorientação de carreira foi delineado. Considerando a literatura, como apontado na introdução com base em Swanson (1995), é problemático dicotomizar a intervenção, uma vez que o AP é um processo muito amplo, incluindo elementos que não são diretamente relacionados à carreira. Por outro lado, a definição implícita de AC pode ser vista como muito estreita, consistindo, primariamente, nas escolhas de uma carreira inicialmente feita por jovens adultos e que, nesse caso, estaria negligenciando o ajustamento necessário ao mundo adulto do trabalho. Jovens e adultos podem necessitar tanto de orientação profissional como de psicoterapia, concomitantemente ou em momentos distintos de suas vidas; o relevante é encontrar os serviços adequados às suas demandas em cada situação.

Observa-se, assim, a necessidade de disponibilizar programas específicos, como os de psicoterapia ou aconselhamento voltados para a clientela adulta que recorre aos serviços de orientação profissional. Com as mudanças vertiginosas na estrutura econômica e nas relações de trabalho, podese aventar a hipótese de que haja uma tendência de crescimento da demanda por adultos que enfrentam intensas dificuldades de crescimento profissional aliadas a questões afetivas.

Considerando o grau de instrução da clientela, a maioria apresentava ensino médio completo ou em curso, o que corresponde ao perfil prevalente da demanda do serviço. Mas é interessante observar que nove clientes tinham nível superior, seis tinham curso universitário em andamento e três já haviam completado o ensino superior. Nesses casos havia também demanda por reorientação de carreira, o que exige do orientador profissional treinamento $\mathrm{e}$ desenvolvimento de habilidades e competências específicas.

Analisando as dificuldades psicológicas apresentadas como justificativa para a realização do encaminhamento, foram referidas, principalmente, queixas associadas a problemas emocionais e comportamentais; dificuldades nos relacionamentos interpessoais nos âmbitos: profissional, familiar e da vida amorosa; e dificuldades escolares. Esses dados são semelhantes aos encontrados pelo estudo pioneiro de Ancona-Lopez (1983) com a clientela 
atendida nas clínicas-escola de psicologia da cidade de São Paulo.

Os dados obtidos indicaram que pouco mais de um terço dos clientes referidos ao SP simplesmente não compareceram à entrevista agendada para triagem, o que sinaliza dificuldade de seguir a recomendação do serviço de referência (SOP), falta de compreensão dos objetivos do encaminhamento ou falta de comprometimento com a intervenção. Esse dado tem implicações diretas no plano terapêutico e na aderência ao tratamento psicológico. Chama a atenção que pouco mais da metade dos clientes encaminhados realmente iniciaram atendimento no SP. Esse dado permite levantar alguns questionamentos: até que ponto o encaminhamento foi de fato compreendido e, sobretudo, aceito pelo cliente? Do ponto de vista subjetivo, o que ocorre nesse intervalo entre buscar um serviço e outro? Como a pessoa percebe o fato de ter recorrido a um serviço especificamente para tratar de questões que, em seu entendimento, eram de natureza ocupacional, e ter recebido como resposta uma indicação e posterior encaminhamento para fazer psicoterapia? Essas indagações precisam ser investigadas por estudos futuros, que abordem esses clientes diretamente, buscando conhecer suas percepções a respeito desse processo.

Uma informação é significativa para o entendimento da dificuldade na adesão ao tratamento por parte dos clientes: o fato do SOP ser um serviço tipicamente desenvolvido por estagiários, em processo de formação profissionalizante - logo, com pouca experiência para lidar com esse processo delicado de encaminhamento. A variável nível de experiência parece interagir com outras variáveis relevantes no processo de atendimento, que podem ser decisivas para a adesão do cliente. Em um estudo de revisão da literatura, foi constatado que há uma "intrigante interação" entre o reconhecimento do problema e a experiência do conselheiro (Llulhier \& Nunes, 2004, p. 48). Por outro lado, cumpre destacar que a segunda entrevista, a de triagem para a Psicoterapia, é feita por um profissional qualificado. Portanto, tal hipótese pode, até certo ponto, ser relativizada. $\mathrm{Na}$ tentativa de compreensão da dificuldade de adesão ao tratamento por parte dos encaminhados pode-se destacar o fato de os clientes serem, em sua maioria, adolescentes, vivendo uma fase peculiar do desenvolvimento humano marcada pela situação de crise de identidade e, particularmente, deve-se ter em conta as características desta pequena amostra de pessoas com problemas emocionais e comportamentais. Para aqueles que não aderiram à psicoterapia parece que a porta de entrada para o atendimento psicológico permanece semiaberta.

Nos 13 casos que aceitaram o encaminhamento sugerido e que efetivamente aderiram ao atendimento psicológico, pode-se conjeturar que a OP configurouse como porta de entrada para psicoterapia (Carvalho, 1995). Ou seja, inicialmente o cliente tinha uma noção de que seu mal-estar psicológico estava relacionado com questões relacionadas à sua identidade ocupacional, não tendo muita clareza de que outros aspectos afetivo-emocionais poderiam estar em jogo. Por outro lado, ao ser esclarecido nesse sentido, mediante um processo de acolhimento realizado pelo serviço, o cliente acata a recomendação do SOP e aceita como razoável a indicação de psicoterapia; assim, implicitamente, concorda com a proposta de redirecionar o escopo do atendimento para abordar questões mais gerais de sua personalidade, de seu modo de ser e de estar no mundo, com a perspectiva de explorar em profundidade seu mundo interior e sua vida de relações.

Dos 13 clientes que compareceram à entrevista inicial no SP, 10 aderiram à psicoterapia até o final do contrato, o que sugere que houve encaminhamento para um tipo de assistência psicológica mais condizente com as necessidades psíquicas da clientela (psicoterapia em vez de OVP), adequada compreensão do encaminhamento efetuado e estabelecimento de uma aliança terapêutica no decorrer do processo psicoterápico. Pode-se considerar que esse dado reflete um resultado auspicioso, uma vez que mostra que a identificação das necessidades do cliente e o diagnóstico do dispositivo de tratamento mais adequado para cada caso contribuem para uma permanência do usuário no serviço, o que aumenta a probabilidade de alcançar os objetivos propostos.

No final de um ano de atendimento, os clientes obtiveram melhora parcial das dificuldades emocionais que justificaram a busca inicial do serviço de psicoterapia, segundo a avaliação dos terapeutas e supervisores. Esse dado pode ser compreendido como um indicador da efetividade da intervenção, uma vez que a psicoterapia de orientação psicodinâmica não almeja a simples remissão dos sintomas, mas a reorganização do setor afetivo-emocional que compõe a personalidade. Evidentemente, essa ambição terapêutica dificilmente é alcançada em um tempo de tratamento tão limitado - menos de um ano. Portanto, o fato de o cliente ter obtido um ajustamento mais satisfatório ao cabo de alguns meses de tratamento deve ser encarado como indício de um resultado satisfatório, de acordo com o padrão esperado para tão pouco tempo de atendimento na abordagem 
psicodinâmica. Pode-se considerar, também, que um dos benefícios alcançados foi a manutenção desses clientes em atendimento contínuo por determinado período de tempo. Para os clientes, esse período pode funcionar como um tratamento de ensaio, uma experiência a ser aprofundada posteriormente, em outros contextos de assistência psicológica em psicoterapia ou em orientação profissional.

De acordo com a literatura, as dificuldades vocacionais/profissionais podem coexistir com outros problemas emocionais (Lucas, 1992). Anderson e Niles (1995) comprovaram tal hipótese ao verificar que mais de um terço das preocupações manifestas por clientes com pedidos vocacionais encontravam-se relacionadas com problemas nãovocacionais, como dificuldades nos relacionamentos interpessoais e/ou outras perturbações emocionais. No presente estudo pôde-se observar a coexistência das dificuldades vocacionais com questões afetivas, em especial com queixas referentes aos relacionamentos interpessoais, familiares, sociais e amorosos, conforme é esperado pela literatura. Para Nascimento e Coimbra (2001), é preciso reconhecer o caráter eminentemente pessoal da problemática vocacional.

Desse modo, é imprescindível realizar uma avaliação para verificar a associação entre a queixa vocacional e demais queixas emocionais e o quanto elas se entrelaçam e interferem umas nas outras e no funcionamento emocional do cliente (Corbishley \& Yost, 1989; Davidson \& Gilbert, 1993; Dorn, 1992; Herr, 1989; Manuele-Adkins, 1992; Spokane, 1989).

No estudo em questão constatou-se que o serviço responsável pelo encaminhamento levou em consideração essas queixas não-vocacionais, sendo que todos os clientes que haviam sido submetidos à triagem psicológica tiveram algum tipo de dificuldade emocional e comportamental reconhecida.

Nascimento e Coimbra (2005b) ressaltam a importância de se proceder a uma análise cuidadosa quando se faz o encaminhamento para outra modalidade de atendimento, pois muitas vezes há o temor de que essa atitude possa desencadear uma mudança ou mesmo uma ruptura no processo de intervenção vocacional. Essa análise deve explorar amplamente os pedidos do cliente, muitas vezes ambíguos e permeados por expectativas nem sempre realistas, criando-se uma atmosfera permissiva e uma relação indutora de confiança, visando minimizar as eventuais resistências à intervenção. Essa visão compreensiva do pedido do cliente pode auxiliar decisivamente no estabelecimento do plano de intervenção e no êxito de sua aplicação. Em todas as situações aqui analisadas o encaminhamento foi feito de maneira cuidadosa, porém, em algumas delas, a estratégia empregada não foi suficiente para assegurar a adesão dos clientes ao outro serviço.

Como descrito anteriormente, para Nascimento e Coimbra (2005a) os motivos que levam as pessoas a procurar ajuda em OVP muitas vezes não são claros, até porque elas não conseguem, na maioria das vezes, identificar suas necessidades dominantes, sendo comum vivenciarem os pedidos vocacionais como menos estigmatizantes e, portanto, mais aceitáveis do que os psicoterápicos (Carvalho, 1995; Davidson \& Gilbert, 1993; Imaginário \& Campos, 1987). Nesse contexto os pedidos de orientação vocacional poderiam traduzir uma resistência à psicoterapia e/ou refletir o fato de que os clientes teriam expectativas de resolução de problemas tanto ocupacionais quanto interpessoais. Esses pedidos também poderiam ser entendidos como uma defesa contra o temor de discriminação social. Nas palavras de Carvalho (1995)

muitas pessoas procuram o Serviço de Orientação Profissional como "uma porta de entrada" para a obtenção de serviços de auxílio psicológico de vários tipos, ou mesmo, de outras áreas. Seja por desconhecimento das diferentes especialidades, seja por medo do estigma da "doença", a orientação profissional lhes parecia oferecer uma oportunidade menos comprometedora de contato com a ajuda psicológica ou psicoterapêutica (p. 167).

No presente estudo considerou-se que o impacto da formulação desse encaminhamento e da clara indicação para psicoterapia parece ter sido vivenciado por alguns clientes como descontinuidade de um processo que se iniciara com a inscrição no SOP. Essa quebra de expectativa, aliada aos estereótipos e possível estigma social que ainda cercam a pessoa que se submete à psicoterapia em nosso contexto cultural, pode estar relacionada ao considerável índice de desistência do atendimento psicológico $(37,5 \%)$, antes mesmo da realização da triagem no SP. Com base na experiência clínica dos autores do presente estudo, pode-se aventar a hipótese de que essas pessoas provavelmente se sentiram desapontadas com o encaminhamento por não vislumbrarem associação imediata entre suas dificuldades, identificadas como eminentemente profissionais, e a indicação de receber psicoterapia. Outra hipótese possível de ser levantada, ainda com base na experiência de mais de duas décadas de atendimento a essa clientela, seria o cliente reconhecer a necessidade de outro tipo de intervenção psicológica, mas não se encontrar em 
situação de implicação subjetiva no atendimento, que leva à adesão e à assunção de responsabilidade para com o próprio tratamento. $O$ que não excluiria a possibilidade de não-adesão à OVP também. Se há outras demandas que não são atendidas, a intervenção em OVP provavelmente não alcançaria resolutividade e, assim, não atenderia às expectativas do cliente. $O$ sentimento de insatisfação estaria presente. Os dados encontrados neste estudo não são suficientes para sustentar essas hipóteses; no entanto, consideramos que elas são pertinentes ao campo investigado e merecem ser exploradas por estudos posteriores.

Caberia, então, ao orientador vocacional identificar a extensão das queixas não-vocacionais do cliente e optar pelo encaminhamento, ou ele próprio intervir nos domínios não-vocacionais, aplicando um processo de psicoterapia, que poderia ocorrer simultaneamente à intervenção vocacional, precedê-la ou ser realizado após o término da mesma (Nascimento \& Coimbra, 2005b). Nessas situações, o orientador profissional que também seja especialista em psicoterapia poderia intervir. Nesses casos, as questões contratuais também deveriam ser repensadas.

A passagem da intervenção vocacional para a psicoterapia pode constituir, assim, um ponto crítico do itinerário do cliente. A atenção do orientador deve ser redobrada, prevenindo possíveis quebras no vínculo, que poderiam, em situações-limite, inviabilizar o processo de ajuda. Nesse momento de transição cabe ao profissional auxiliar o cliente "a compreender a inseparabilidade da dimensão vocacional relativamente a outras dimensões pessoais"; assim, "talvez a intervenção contribua para fazê-lo desistir dos esforços para estancar a sua vida profissional e pessoal" (Nascimento \& Coimbra, 2005b, p. 26).

Além disso, acredita-se que a psicoterapia, aliada ao processo de OVP, pode auxiliar na promoção e mobilização dos recursos internos dos clientes, otimizando o seu desempenho no processo de orientação vocacional (Corbishley \& Yost, 1989; Dorn, 1992; Nascimento \& Coimbra, 2001). As potencialidades do uso combinado de diferentes estratégias de intervenção precisam ser mais bem exploradas em novos estudos. É evidente que cada situação deve ser cuidadosamente analisada. Há situação com grau de comprometimento afetivoemocional tão acentuado que inviabilizaria tal caminho. Às vezes estratégias combinadas podem ser eficazes, dependendo da natureza do problema, da disponibilidade do cliente e da experiência e competência dos profissionais envolvidos. Alguns cuidados devem ser tomados se a opção for estratégias combinadas: (1) garantia de que o cliente tenha visão clara das duas modalidades de intervenção e que os dois profissionais saibam de seus limites e possibilidades; (2) de preferência, se for possível, que a intervenção em OVP seja em grupo, para se diferenciar da psicoterapia, porém essa sugestão só é exequível se o cliente tem perfil psicológico e disponibilidade para intervenção grupal.

De acordo com os resultados da presente investigação, dos 13 clientes que iniciaram o processo psicoterapêutico, 10 completaram o programa de intervenção proposto pelo SP com melhora parcial dos sintomas, resultado que pode ser interpretado como evidência do valor positivo da articulação existente entre os serviços.

Conclui-se que o SP, no período avaliado, mostrou ser um recurso eficiente no atendimento da demanda oriunda do SOP, constituindo uma alternativa complementar para aqueles casos que necessitam de uma abordagem que focalize as questões de cunho afetivo-emocional e aderem a ambas as intervenções. A sobreposição das duas áreas, necessárias para lidar com os problemas pessoais e profissionais - trazidos por parte significativa dos usuários, reforça a importância da formação em psicologia para a intervenção em OVP no âmbito da promoção de saúde. Essa assertiva é válida para alguns modelos teóricos, como o clínico, que demandam conhecimentos específicos acerca do funcionamento mental. Já a atuação em contextos educativos e organizacionais permite também a intervenção de profissionais oriundos de outras formações básicas.

Uma das limitações deste estudo é o fato dele abarcar uma única instituição. Sugere-se que estudos futuros contemplem outros centros de atendimentos para verificar diferenças no perfil sociodemográfico dos clientes. Outra limitação é que os resultados não podem ser generalizados. Seria interessante o desenvolvimento de estudos multicêntricos, com um número maior de clientes, e delineamentos prospectivos, que possibilitem comparar o desfecho de clientes que aderiram com o de clientes que não aderiram à intervenção psicológica preconizada.

\section{Referências}

Ancona-Lopez, M. (1983). Consideração sobre o atendimento fornecido por clínicas-escolas de psicologia. Arquivos Brasileiros de Psicologia, 35(2), 123-135. 
Anderson, W. P. \& Niles, S. G. (1995). Career and personal concerns expressed by career counseling clients. The Career Development Quarterly, 43(3), 240-245.

Antunes, J. B., Valdo, M. \& Melo-Silva, L. L. (2003). Uma experiência de orientação profissional em grupo. Em L. L. Melo-Silva, M. A. Santos, J. T. Simões \& M. C. Avi (Orgs.). Arquitetura de uma ocupação: orientação profissional - teoria e prática (pp. 343-362). São Paulo: Vetor.

Betz, N. \& Corning, A. (1993). The inseparability of "career" and "personal" counseling. The Career Development Quarterly, 42(1), 137-142.

Bohoslavsky, R (2003). Orientação vocacional: a estratégia clínica (11 ${ }^{\mathrm{a} e d}$.). São Paulo: Martins Fontes.

Carvalho, M. M. M. Y. (1995). Orientação profissional em grupo: teoria e técnica. Campinas: Psy.

Casullo, M. M., Cayssials, A. N., Liporace, M. F., Diuk, L. W., Michel, J. A. \& Álvarez, L. (2006). Proyecto de vida y decisión vocacional. Buenos Aires: Paidós.

Corbishley, M. A. \& Yost, E. B. (1989). Psychological aspects of career counseling. Journal of Career Development, 16(1), 43-51.

Davidson, S. \& Gilbert, L. (1993). Career counseling is a personal matter. The Career Development Quarterly, 42(2), 149-153.

Dorn, F. J. (1992). Occupational wellness: the integration of career identity and personal identity. Journal of Counseling and Development, 71(1), 176-178.

Gold, J. M. \& Scanlon, C. R. (1993). Psychological distress and counselling duration of career and noncareer clients. The Career Development Quarterly, 42, 186-191.

Hackett, G. (1997). Self-efficacy in career choice and development. Em A. Bandura (Ed.). Self-efficacy in changing societies. New York: Cambridge University Press.

Herr, E. L. (1989). Career development and mental health. Journal of Career Development, 16(1), 5-18.

Imaginário, L. \& Campos B. P. (1987). Consulta psicológica vocacional em contexto escolar. Cadernos de Consulta Psicológica, 3(1), 107-113.

Lucas, M. S. (1992). Problems expressed by career and non-career help seekers: a comparison. Journal of Counseling and Development, 70(1), 417420.

Llulhier, A. C. \& Nunes, M. L. T. (2004). Uma aliança que se rompe. Ciência e Profissão: Diálogos, 1, 43-49.
Manuele-Adkins, C. (1992). Career counseling is personal counseling. The Career Development Quarterly, 40(1), 313-323.

Melo-Silva, L. L. (1999). Estágio profissionalizante em orientação profissional: experiência em um curso de psicologia (I). Revista da ABOP, 3(1), 119-35.

Melo-Silva, L. L. (2005). Orientação profissional em uma clínica-escola de psicologia. Em Melo-Silva, L. L., Santos, M. A. \& Simon, C. P. Formação em psicologia: serviços-escola em debate. São Paulo: Vetor.

Melo-Silva, L. L., \& Jacquemin, A. (2001). Intervenção em orientação vocacional/profissional: avaliando processos e resultados. São Paulo: Vetor.

Müller, M. (1988). Orientação vocacional: contribuições clínicas. Porto Alegre: Artes Médicas.

Müller, M. (1994). Descubrir el camino: nuevos aportes educacionales y clínicos de orientación vocacional. Buenos Aires: Bonum.

Müller, M. (2007). Orientación vocacional: aportes clinicos e vocacionale. Buenos Aires: Miño y Dávila.

Nascimento, I. \& Coimbra, J. L. (2001). O reconhecimento do carácter eminentemente pessoal da problemática vocacional. Em C. Borrego, J. L. Coimbra \& D. Fernandes (Orgs.). Construção de competências pessoais e profissionais para o trabalho. Actas, II Encontro Internacional de Formação Norte de Portugal/ Galiza. Galiza (p. 89). Portugal: Instituto de Emprego e Formação Profissional, Delegação do Norte.

Nascimento, I. \& Coimbra, J. L. (2005a). Pedidos, problemas e processos: alguns dilemas da intervenção em consulta psicológica vocacional. Revista Brasileira de Orientação Profissional, 6(2), 1 14.

Nascimento, I. \& Coimbra, J. L. (2005b). A escolha do foco de intervenção em consulta psicológica vocacional: contributos para uma perspectiva integradora da intervenção Revista Brasileira de Orientação Profissional, 6(2), 15-30.

Osipow, S. H. \& Gold, J. A. (1968). Personal adjustment and career development. Journal of Counseling Psychology, 15(1), 439-443.

Pichon-Rivière, E. (1994). O processo grupal. 5a . ed. São Paulo: Martins Fontes.

Pichon-Rivière, E. (1995). Teoria do vinculo. 5a . ed. São Paulo: Martins Fontes.

Santos, M. A (2007) Psicoterapia psicanalítica: aplicações no tratamento de pacientes com problemas relacionados ao uso de álcool e outras 
drogas. SMAD, Revista Eletrônica Saúde Mental Álcool e Drogas [Online], 3(1). Obtido em 28 de abril de 2008 do World Wide Web: http://pepsic.bvs-psi.org.br/scielo.php?script= ci_arttext\&pid=S1806-69762007000100006

\&Ing=pt\&nm=iso. ISSN 1806-6976.

Santos, M. A. \& Oliveira, E. A. (2005). Serviço de Triagem de Adultos e Adolescentes: panorama histórico de uma clínica psicológica. Em L. L. Melo-Silva, M. A. Santos, \& C. S. Paulin (Orgs.), Formação em Psicologia: Serviços-escola em debate (pp. 279-298). São Paulo: Vetor.

Santos, M. A.; Pasian, S. R.; Oliveira, E. A.; MeloSilva, L. L. \& Garducci, P. C. (2005). A trajetória do cliente na clínica-escola: Articulação entre serviços na formação profissionalizante em Psicologia. Em L. L. Melo-Silva, M. A. Santos \& C. S. Paulin (Orgs.), Formação em Psicologia: serviçosescola em debate (pp. 123-154). São Paulo: Vetor.

Spokane, A. (1989). Are there psychological ad mental health consequences of difficult career decisons? Journal of Career Development, 16(1), 1923.

Swanson, J. L. (1995). The process and outcome of career counseling. Em W. B. Walsh \& S. H. Osipow (Eds.). Handbook of vocational psychology: theory, research, and practice (2nd ed.) (pp. 217259). Mahwah, New Jersey: Lawrence Erlbaum Associates.

Recebido em dezembro de 2008 Reformulado em março de 2009 Aprovado em maio de 2009

Sobre os autores:

Manoel Antônio dos Santos é professor doutor do Departamento de Psicologia e Educação da Faculdade de Filosofia, Ciências e Letras de Ribeirão Preto, Universidade de São Paulo (FFCLRP-USP), orientador do Programa de Pós-graduação em Psicologia, coordenador do Núcleo de Ensino e Pesquisa em Psicologia da Saúde (NEPPS)-CNPq, bolsista de Produtividade em Pesquisa do CNPq, editor da Paideia.

Érika Arantes de Oliveira Cardoso é doutora em Psicologia pela Universidade de São Paulo, Ribeirão PretoSP, psicóloga do Núcleo de Ensino e Pesquisa em Psicologia da Saúde (NEPPS)-CNPq da Faculdade de Filosofia, Ciências e Letras de Ribeirão Preto, Universidade de São Paulo (FFCLRP-USP).

Lucy Leal Melo-Silva é professora doutora do Departamento de Psicologia e Educação da Faculdade de Filosofia, Ciências e Letras de Ribeirão Preto, Universidade de São Paulo (FFCLRP-USP), orientadora do Programa de Pós-Graduação em Psicologia, bolsista de Produtividade em Pesquisa do CNPq e editora da Revista Brasileira de Orientação Profissional. 